\title{
VIABILITY OF SH-SY5Y CELLS IS ASSOCIATED WITH PURINERGIC P2 RECEPTOR EXPRESSION ALTERATIONS
}

\author{
Arda Örçen, ${ }^{1}$ Vuslat Yilmaz,,${ }^{1}$ Murat Giriș, ${ }^{1}$ UĞUr AKCan, ${ }^{1}$ \\ ERDEM TÜZÜN ${ }^{1}$ and GAYE ERTEN ${ }^{2}$,* \\ ${ }^{1}$ Department of Neuroscience, Aziz Sancar Institute of Experimental Medicine, Istanbul University, \\ Istanbul, Turkey \\ ${ }^{2}$ Department of Immunology, Aziz Sancar Institute of Experimental Medicine, Istanbul University, \\ Istanbul, Turkey
}

(Received: August 23, 2016; accepted: October 13, 2016)

\begin{abstract}
To investigate the role of metabotrophic purinergic P2Y receptors in neuroblastoma cell survival, expression of $\mathrm{P} 2$ receptors by normal mouse (C57BL/6) brain and human neuroblastoma SH-SY5Y cells was investigated by Western blot and real time PCR studies. Viability of SH-SY5Y cells treated with purinergic receptor antagonists suramin and pyridoxal-phosphate-6-azophenyl-2',4'-disulfonate (PPADS) was evaluated by MTT assay and flow cytometry. In the brain samples of C57BL/6 mice, expressions of P2Y4 and $\mathrm{P} 2 \mathrm{X} 7$ were significantly reduced, whereas that of $\mathrm{P} 2 \mathrm{Y} 1$ was significantly elevated in an age-dependent manner. SH-SY5Y cell viability was significantly reduced and necrotic cell rates were mildly increased by $400 \mu \mathrm{M}$ suramin and $100 \mu \mathrm{M}$ PPADS treatment. Antagonist treatment downregulated P2Y1, P2Y2 and P2Y4 and upregulated P2Y6, P2Y12 and P2X7 mRNA levels in SH-SY5Y cells on the 24th hour. These alterations were abolished for all P2 receptors except P2Y1 in the 48th hour. P2Y receptors are expressed by both normal mouse brain and human neuroblastoma cells. Purinergic receptor antagonism interferes with neuroblastoma viability through elevation of necrotic cell death and modulation of $\mathrm{P} 2$ receptor expression. $\mathrm{P} 2 \mathrm{Y}$ receptors might thus be useful targets for future anti-tumor treatment trials.
\end{abstract}

Keywords: Neuroblastoma - SH-SY5Y - purinergic receptor - MTT-viability

\section{INTRODUCTION}

Purinergic signalling is critical for proper functioning of the nervous system. Purinergic receptors play crucial roles in a variety of neurological disorders such as epilepsy and depression and contribute to the progression of several types of tumors such as glioma and neuroblastoma [11]. Moreover, recent evidence suggests that disturbance of the P2Y and P2X receptor signalling and changes in expression of extracellular ectonucleotidases interfere with normal neuronal aging and facilitate neurodegeneration [14].

Neuroblastoma is a malignant tumor originating from neuroectodermal cells, and it is the second most common solid tumor in children and is commonly associated with high rates of metastasis and low rates of survival despite early diagnosis and

\footnotetext{
*Corresponding author; e-mail address: gerten@istanbul.edu.tr
} 
intensive cancer therapy [8]. The control of neuroblastoma progression involves several intracellular signalling pathways, including those related with purinergic P2 receptors $[1,3-5,7,12]$. Although ATP is secreted in an autocrine fashion to achieve certain physiological functions, it is present at almost undetectable level in the normal interstitial tissue [10]. By contrast, ATP released from tumor cells is accumulated at the interstitium of the cancer tissue (including that of neuroblastoma) at very high concentrations and plays an important role in tumor progression [3].

In this study, first, expression of purinergic P2 receptors that are known to be involved in cell viability $[1,3-5,7,11,12]$ was examined in the aging mouse brain. Next, we identified the impact of $\mathrm{P} 2$ receptor antagonists on the viability, cell death and purinergic receptor expression of human SH-SY5Y neuroblastoma cells. Our results emphasize $\mathrm{P} 2 \mathrm{Y}$ receptors as major role players in neuroblastoma progression and a potential target in anti-tumor therapy.

\section{MATERIAL AND METHODS}

\section{Mice}

Expression levels and age-dependent variations of several purinergic receptors were investigated in the mouse brain due to unavailability of human tissue samples. Male C57BL/6 (B6) mice from different ages (3, 9 and 15 month-old; $n=5$ for each age group) were obtained from the animal facility of Aziz Sancar Institute of Experimental Medicine. Mice were housed in a viral antibody-free barrier facility and maintained according to the Institutional Animal Care and Use Committee Guidelines. The study was approved by the Institutional Review Board.

\section{Immunoblotting analyses}

Brain samples were rapidly obtained from each mouse following decapitation and protein concentrations were determined with a BCA detection kit. Twenty micrograms of each brain lysate was loaded and separated by 4-20\% SDS-polyacrylamide gradient gel electrophoresis and then transferred to $0.45 \mu \mathrm{m}$ polyvinylidene fluoride membranes $(100 \mathrm{~V}, 80 \mathrm{~min})$. After blocking for 1 hour in PBST (10 mm sodium phosphate, $0.9 \% \mathrm{NaCl}$ and $0.1 \%$ Tween 20 ) containing $5 \%$ non-fat dry milk, blots were incubated overnight at $4{ }^{\circ} \mathrm{C}$ with goat anti-mouse P2Y1, P2Y2, P2Y4, P2Y6, P2Y12, P2X7 and $\beta$-actin (Santa Cruz Biotechnology, Santa Cruz, CA, USA) antibodies in PBST containing 5\% non-fat milk. The blots were washed with PBST and incubated for 1 hour with horseradish peroxidase-conjugated rabbit anti-goat (Santa Cruz Biotechnology) diluted in PBST. Immunoreactivity of the protein bands were detected by enhanced chemiluminescent autoradiography (ECL kit, Amersham Pharmacia Biotech, Piscataway, NJ). A molecular weight standard (Bio-Rad Laboratories, Hercules, CA) was used to evaluate the molecular weight of detected 
bands. The immunoblot bands were quantified through measurement of band intensity with ImageJ software using the same pixel scale for all pictures. Band intensities were normalized by $\beta$-actin expression and expressed as arbitrary units.

\section{Cell viability assessment}

Human SH-SY5Y cells (ATCC, Wesel, Germany) were grown in DMEM/F12 (1:1) media supplemented with $10 \%$ fetal bovine serum, $100 \mathrm{U} / \mathrm{ml}$ penicillin, and $100 \mu \mathrm{g} /$ $\mathrm{ml}$ streptomycin. The cells were plated in 96-well plates at a density of $1 \times 10^{5}$ cells/ well with or without $\mathrm{P} 2$ purinergic receptor antagonists suramin $(400 \mu \mathrm{M})$ or pyridoxal-phosphate-6-azophenyl-2',4'-disulfonate (PPADS) $(100 \mu \mathrm{M})$ for 12, 24, 48 and 72 hours. The plated cells were maintained at $37{ }^{\circ} \mathrm{C}$ in $95 \%$ humidified atmosphere with $5 \% \mathrm{CO}_{2}$. Six separate wells were used for each antagonist and time duration. Antagonist concentrations were selected according to results obtained in preliminary experiments. The media was changed with one containing $0.5 \mathrm{mg} / \mathrm{ml}$ MTT (3-[4,5-dimethylthiazol-2-yl]-2,5-diphenyl tetrazolium bromide). Four hours later, the media was gently removed and the precipitations in each well were dissolved in $100 \mu \mathrm{l}$ of DMSO. The absorbance at $570 \mathrm{~nm}$ was measured using a microplate reader and expressed as OD.

\section{Flow cytometry}

In a second experiment, SH-SY5Y cells were plated in 96-well plates at a density of $1 \times 10^{5}$ cells/well and treated with or without $400 \mu \mathrm{M}$ suramin and $100 \mu \mathrm{M}$ PPADS for 24 or 48 hours. Six separate wells were used for each antagonist and time duration. After treatment, cells were collected and washed with cold PBS. Annexin V-fluorescein isothiocyanate (FITC; $5 \mu \mathrm{L}$ ) and propidium iodide (PI) staining solution $(5 \mu \mathrm{L})$ were added and cells were then incubated for 20 minutes in the dark. The apoptosis and necrosis rates were measured through flow cytometry (Beckman, Brea, CA).

\section{Real time PCR}

In the last experiment performed using the same experimental setting in 96-well plates (six wells for each parameter), SH-SY5Y cells were collected after incubation with or without $400 \mu \mathrm{M}$ suramin and $100 \mu \mathrm{M}$ PPADS for 24 or 48 hours. Total RNA from each well was isolated using Trizol Reagent (InVitrogen, Carlsbad, CA, USA) and RNA was quantified by OD260. Four micrograms of total mRNA were reverse transcribed using superscript II reverse transcriptase and oligodT primer (InVitrogen). Specific primers (Table 1) were selected using primer3 software and generated by Qiagen (Hilden, Germany). The specificity of the primers was verified with a Blast 
Table 1

Quantitative polymerase chain reaction primers

\begin{tabular}{|c|c|c|}
\hline Primer name & Forward primer (5'-'3) & Reverse primer (3'-'5) \\
\hline P2Y1 & CGACAGGGTTTATGCCACTT & TCGTGTCTCCATTCTGCTTG \\
\hline P2Y2 & AGCCCATTACGTGACTGTCC & CTGAGGCAGGAAACAGGAAG \\
\hline P2Y4 & AACCAGGAAGCTGGGGTACT & GGAGGTTCCTTAGGGTCAGC \\
\hline P2Y6 & GGAACACCAAATCTGGCACT & GTATACCGGGGTTAGCAGCA \\
\hline P2Y12 & TGGGCGTACCCTACAGAAAC & AGGTGGTATTGGCTGAGGTG \\
\hline P2X7 & CCACCTTCAAAACCACGTCT & AAGCTCTTTTCCCACCCCTA \\
\hline GAPDH* & AGGGCTGCTTTTAACTCTGGT & CCCCACTTGATTTTGGAGGGA \\
\hline
\end{tabular}

*Indicates housekeeping gene GAPDH, glyceraldehyde 3-phosphate dehydrogenase.

search through NCBI. The quantitative real-time PCR reactions were performed with the SYBR Green kit (Roche Diagnostics, Mannheim, Germany) using $2 \mu 1$ of cDNA and $0.6 \mu \mathrm{l}$ of each primer in a $20 \mu \mathrm{l}$ final volume. Quantitative PCR was performed using Light Cycler (Roche Diagnostics) for 40 cycles at $95{ }^{\circ} \mathrm{C} 15$ seconds, annealing temperature of $60^{\circ} \mathrm{C}$ for 20 seconds and $72{ }^{\circ} \mathrm{C}$ for 30 seconds. All samples were studied as duplicates and glyceraldehyde 3-phosphate dehydrogenase (GAPDH) was used as a reference gene. Data were analyzed according to the $\Delta \Delta \mathrm{Ct}$ method and the results were expressed as relative mRNA levels.

\section{Statistical analysis}

Multiple group comparisons among different treatment arms were performed with ANOVA and Tukey's post-hoc test. $p$ values for ANOVA are provided in the text, whereas $p$ values for two-group comparisons are indicated in the figures. $p<0.05$ was considered as statistically significant.

\section{RESULTS}

\section{Age-dependent variation of cerebral $P 2$ receptor expression}

The presence and expression levels of major cell survival-related purinergic $\mathrm{P} 2$ receptors in the mouse brain were investigated by immunoblotting analyses using a semiquantitative measurement method. Brain samples of mice from different ages exhibited P2Y1, P2Y2, P2Y4, P2Y6, P2Y12 and P2X7 receptors at varying expression levels. Notably, expression levels of P2Y1, P2Y2 and P2Y6 receptors showed trends towards increasing, while those of $\mathrm{P} 2 \mathrm{Y} 4$ and $\mathrm{P} 2 \mathrm{X} 7$ showed trends towards decreasing 

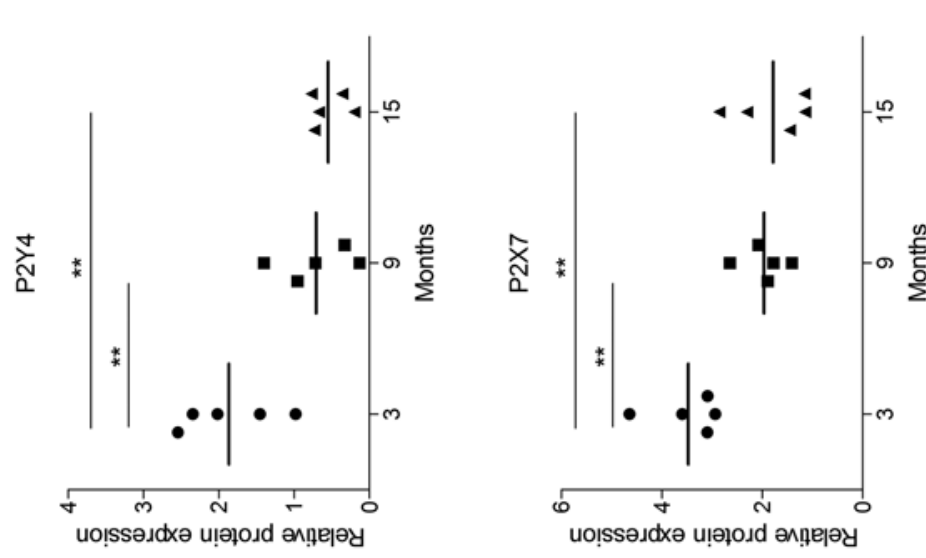

플 욤

of

言

르응

$\stackrel{\oplus}{\square}$

言

की

응

융

吾

完:
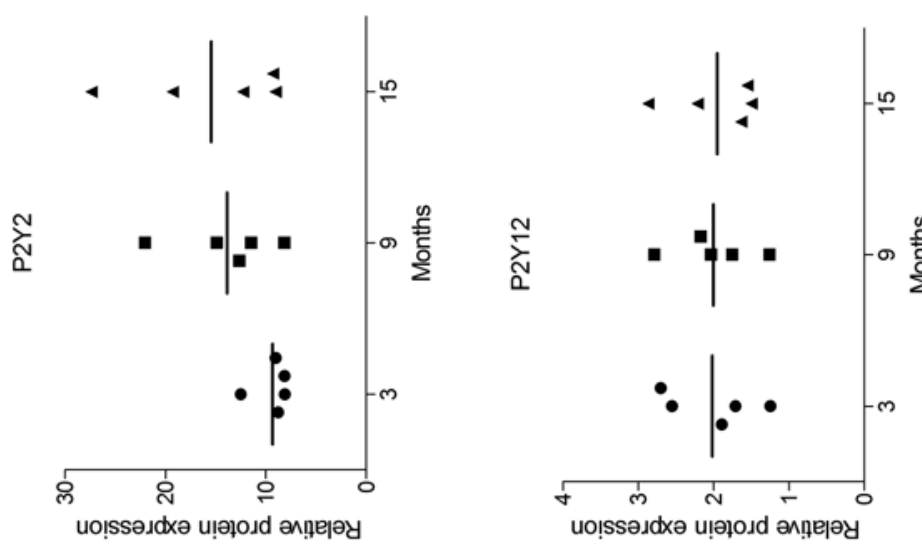

䒕

完焉

की

艺可

ए

矛合

4 릉

岂

.

홍
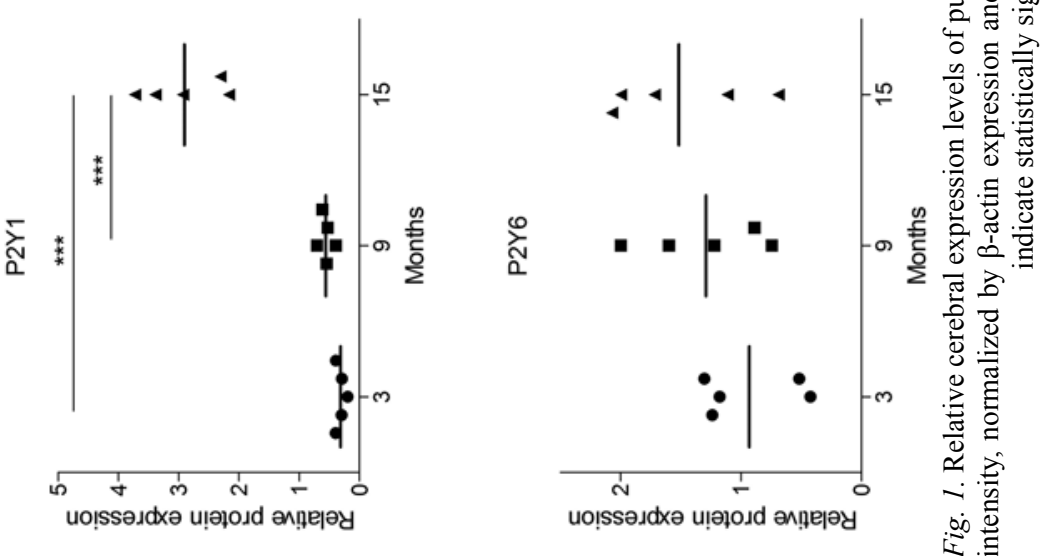

Acta Biologica Hungarica 68, 2017 
in an age-dependent manner and P2Y12 expression levels remained stable at different ages. These alterations attained statistical significance only for P2Y1, P2Y4 and P2X7 receptors ( $p<0.001, p=0.002$ and $p=0.003$, respectively) (Fig. 1).

\section{Cell viability of SH-SY5Y cells are reduced by P2 receptor antagonists}

The impact of purinergic P2 receptor antagonists on SH-SY5Y cell viability was assessed by MTT assay. Both suramin and PPADS significantly suppressed SH-SY5Y viability by the 12 th and 24 th hours ( $p<0.001$ for both time points). At the 48th hour, PPADS treated cells continued displaying reduced viability as compared to nontreated and suramin-treated cells $(p<0.001)$. By the 72nd hour, all treatment arms showed comparable viability levels $(p=0.355$, Fig. 2). MTT experiments also showed that the critical time for the alteration of cellular proliferation for antagonist administered SH-SY5Y cells was 24-48 hours. Therefore remaining experiments were done for these two specific time points.

\section{$P 2$ receptor antagonists induce a moderate increase in SH-SY5Y necrosis rates}

To evaluate whether cell viability reduction of P2 receptor antagonist administered SH-SY5Y cells was due to necrotic or apoptotic cell death, flow cytometry analysis was performed using PI-Annexin V staining. No appreciable apoptotic (Annexin V+ cells) cell death was observed in SH-SY5Y cells treated with or without purinergic P2 receptor antagonists at the 24th and 48th hours of incubation (Table 2). By contrast, treatment with both $400 \mu \mathrm{M}$ suramin and $100 \mu \mathrm{M}$ PPADS induced mildly but significantly increased necrosis (PI+Annexin V-cells) rates as compared to nontreated cells at the 24th hour of incubation (Fig. 3). However, the necrosis rate difference between treatment groups was abolished on the 48th hour of incubation (Table 2).

Table 2

Necrotic and apoptotic cell death rates of purinergic receptor antagonist administered SH-SY5Y cells as assessed by flow cytometry analysis of propidium iodide (PI) and Annexin V staining

\begin{tabular}{|l|c|c|c|c|c|c|}
\hline \multirow{2}{*}{} & \multicolumn{3}{|c|}{24 hours } & \multicolumn{3}{c|}{48 hours } \\
\cline { 2 - 7 } & $\begin{array}{c}\text { PI+ } \\
\text { Annexin V- }\end{array}$ & $\begin{array}{c}\text { PI+ } \\
\text { Annexin V+ }\end{array}$ & $\begin{array}{c}\text { PI- } \\
\text { Annexin V+ }\end{array}$ & $\begin{array}{c}\text { PI+ } \\
\text { Annexin V- }\end{array}$ & $\begin{array}{c}\text { PI+ } \\
\text { Annexin V+ }\end{array}$ & $\begin{array}{c}\text { PI- } \\
\text { Annexin V+ }\end{array}$ \\
\hline None & $6.9 \pm 0.2$ & $0.1 \pm 0.1$ & $0.0 \pm 0.0$ & $9.6 \pm 0.8$ & $0.1 \pm 0.1$ & $0.1 \pm 0.1$ \\
\hline $\begin{array}{l}400 \mu \mathrm{M} \\
\text { suramin }\end{array}$ & $11.1 \pm 0.3$ & $0.2 \pm 0.1$ & $0.1 \pm 0.1$ & $9.9 \pm 0.5$ & $0.1 \pm 0.1$ & $0.1 \pm 0.1$ \\
\hline $\begin{array}{l}100 \mu \mathrm{M} \\
\text { PPADS }\end{array}$ & $12.3 \pm 0.8$ & $0.1 \pm 0.1$ & $0.0 \pm 0.0$ & $10.3 \pm 0.8$ & $0.1 \pm 0.1$ & $0.1 \pm 0.1$ \\
\hline$p$ value & $<0.001$ & 0.776 & 0.861 & 0.196 & 0.854 & 0.957 \\
\hline
\end{tabular}

PPADS, pyridoxal-phosphate-6-azophenyl-2',4'-disulfonate. Data are expressed as mean \pm standard deviation. 

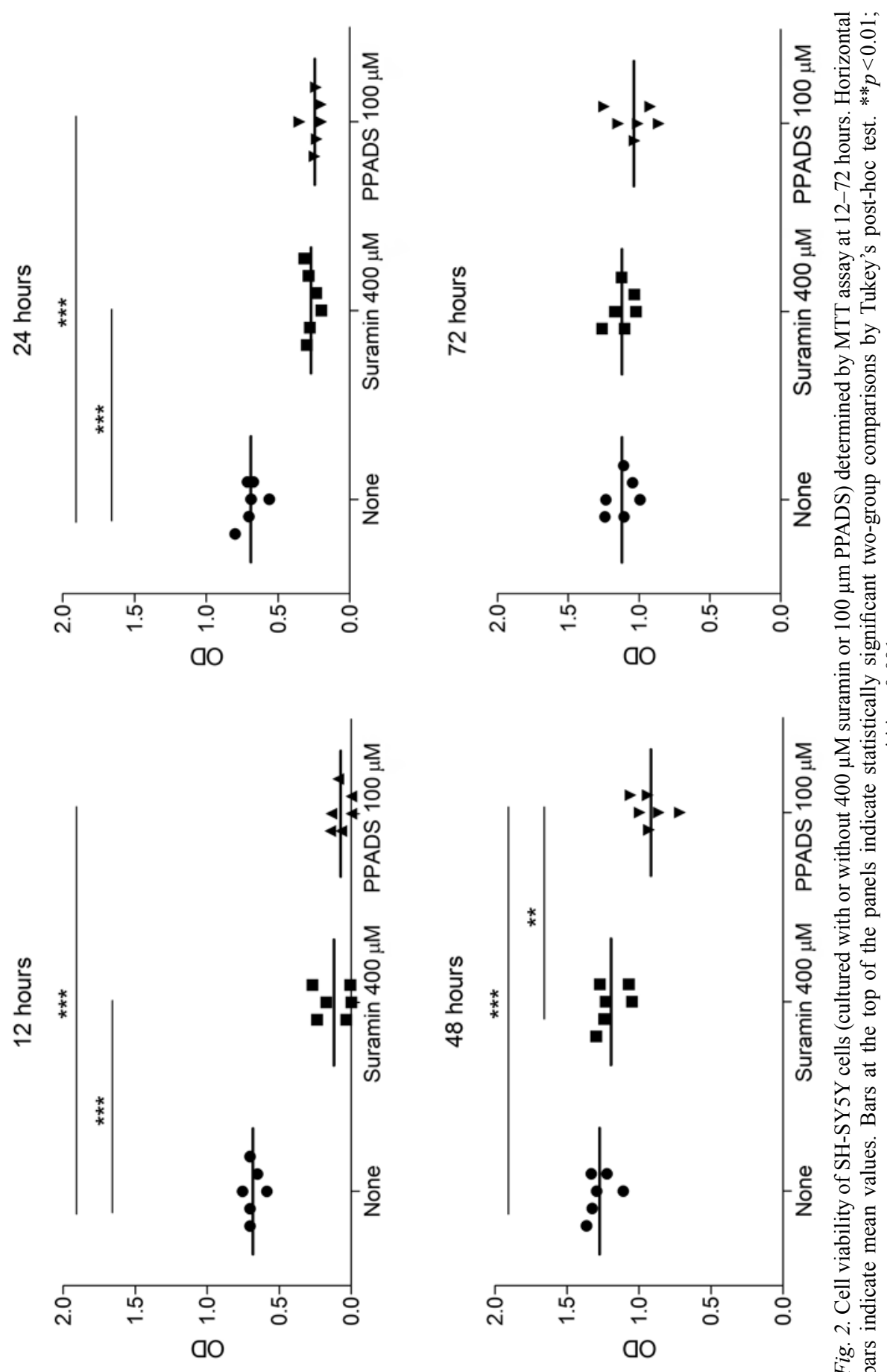

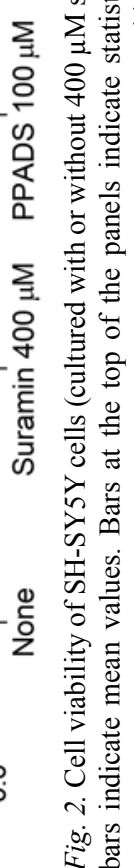

Acta Biologica Hungarica 68, 2017 

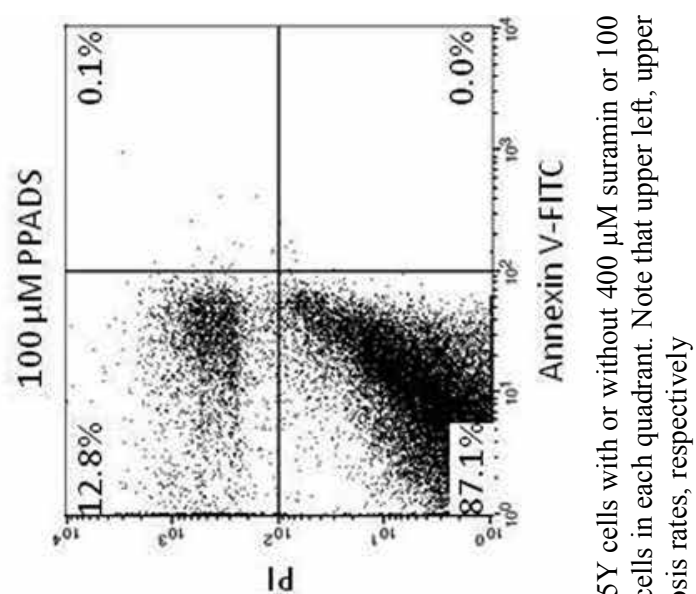

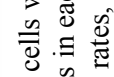

in $\frac{n}{8}$

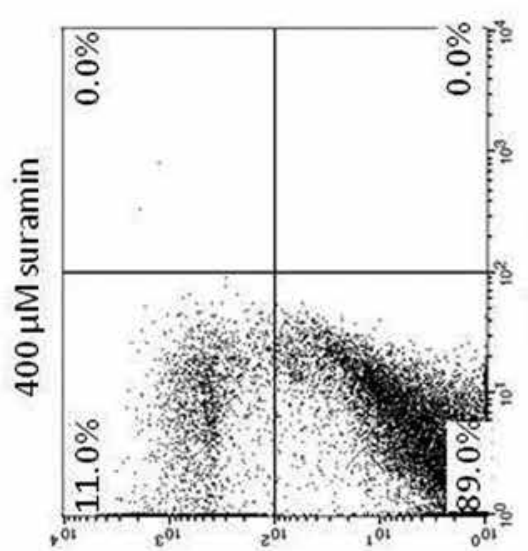

全

峦

:

ᄂ

눌 昰

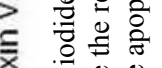

竞莺

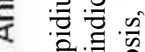

㝴苛

च

$>$ 至

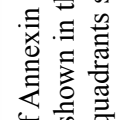

Id

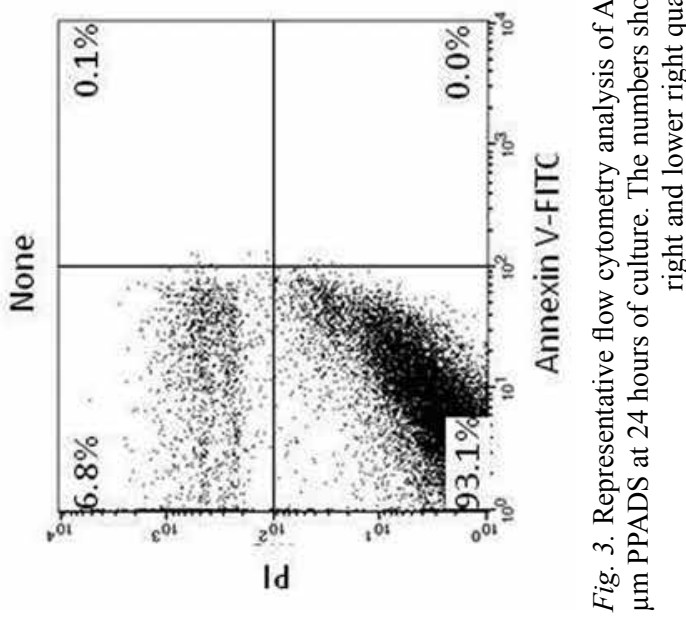

Acta Biologica Hungarica 68, 2017 

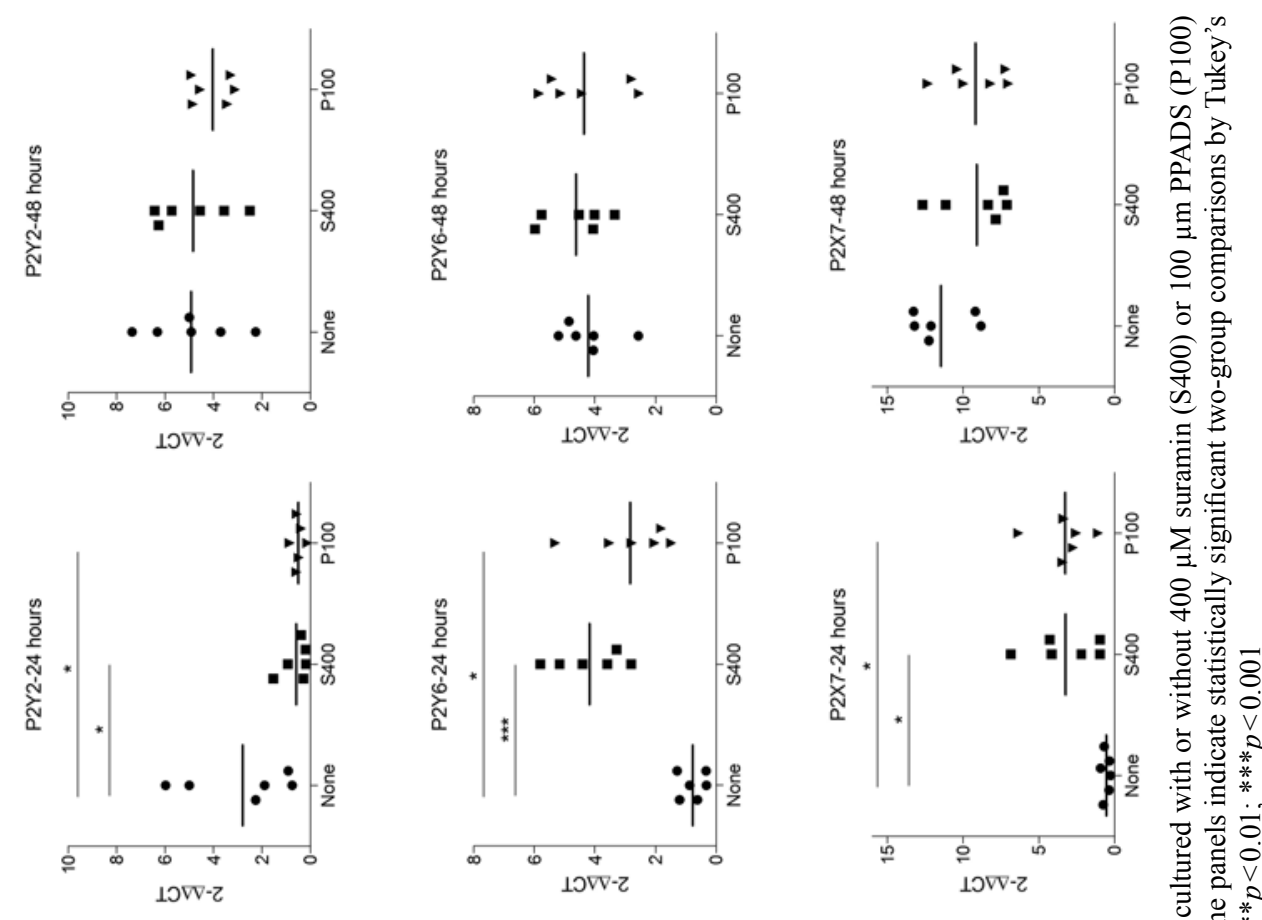

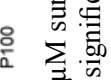
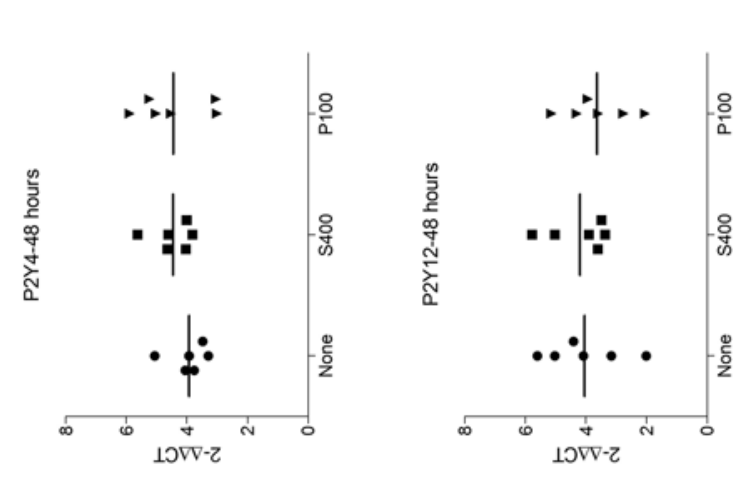

우을
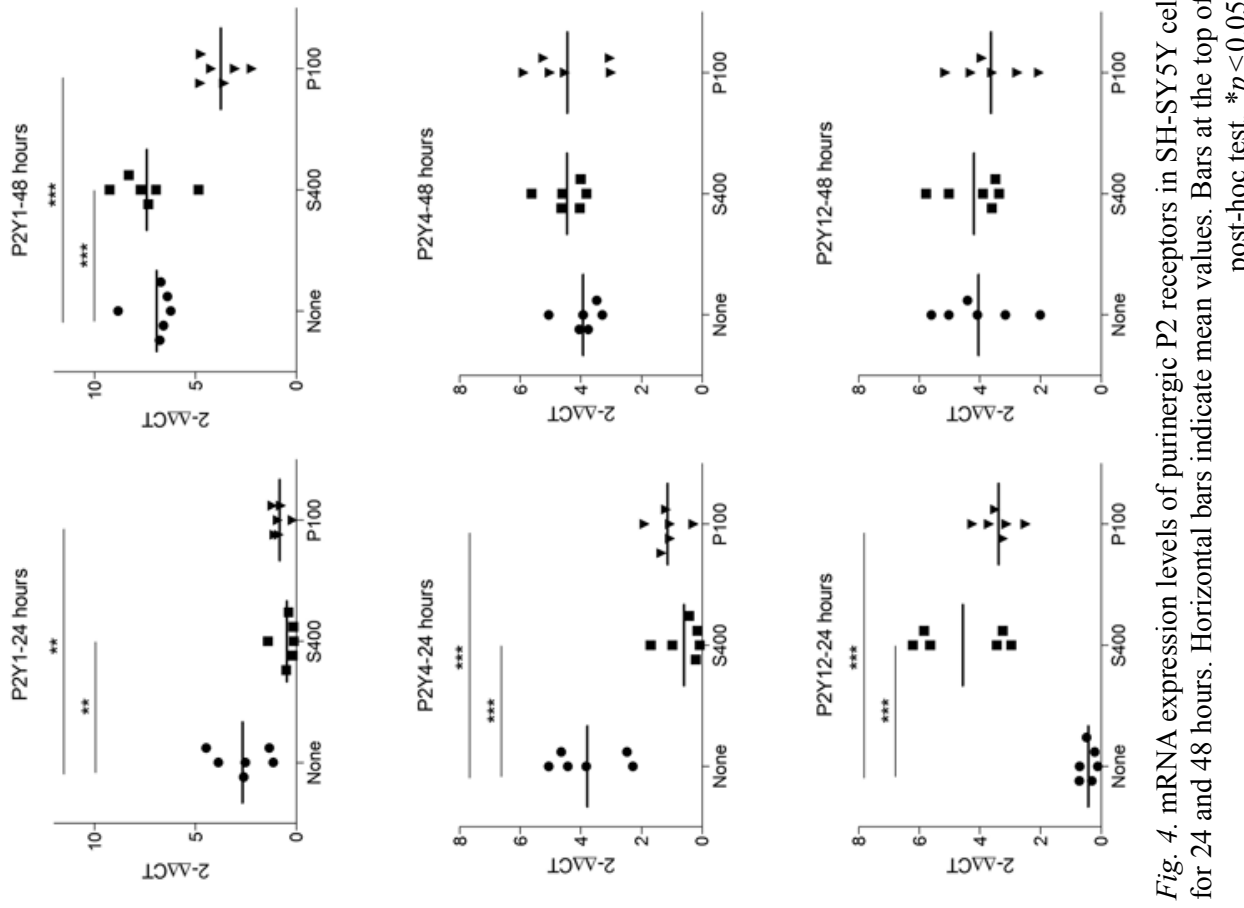

Acta Biologica Hungarica 68, 2017 


\section{P2 receptor expression variations of antagonist-treated $\mathrm{SH}-\mathrm{SY} 5 \mathrm{Y}$ cells}

Impact of purinergic P2 receptor antagonists on expression levels of various P2 receptors was evaluated by real time PCR studies with the same experimental setting used in previous experiments. At the 24th hour of incubation, both suramin and PPADS-treated SH-SY5Y cells showed significantly reduced P2Y1 $(p=0.001)$, P2Y2 $(p=0.012)$ and P2Y4 $(p<0.001)$ expression levels and significantly increased $\mathrm{P} 2 \mathrm{Y} 6(p<0.001), \mathrm{P} 2 \mathrm{Y} 12(p<0.001)$ and $\mathrm{P} 2 \mathrm{X} 7(p=0.019)$ expression levels. These differences were abolished on 48th hour of incubation for P2Y2 $(p=0.521)$, P2Y4 $(p=0.489), \mathrm{P} 2 \mathrm{Y} 6(p=0.830), \mathrm{P} 2 \mathrm{Y} 12(p=0.678)$ and $\mathrm{P} 2 \mathrm{X} 7(p=0.122)$ receptors. By contrast, PPADS-treated cells showed significantly lower P2Y1 expression levels $(p<0.001)$ than suramin-treated and non-treated cells at the 48th hour of incubation (Fig. 4).

\section{DISCUSSION}

Neuronal vulnerability is known to increase by advancing age and the purinergic signalling is one of the mechanisms by which this is evoked. In the aging brain cells, interstitial ATP concentrations as well as purinergic receptor and neurotransmitter expression levels have been shown to change in parallel to each other [9]. In our study, we have shown that expression levels of most purinergic P2 receptors do not exhibit a steady-state pattern and show variations throughout the life span of mice. This might presumably be a compensatory adaptation for different neuronal proliferation requirements in the advancing stages of life. P2X7 has been strongly associated with neuronal cell viability $[3,5,7,12]$ and thus decreased expression of P2X7 might be one of the factors causing neuronal cell loss in advanced ages. In viability assays, P2Y1 downregulation was associated with reduced neuroblastoma cell survival and increased necrosis. Upregulation of this receptor might potentially be a compensating mechanism to counteract increasing neuronal death in the aging mouse brain. The validity of these assumptions and meaning of P2 receptor expression changes at different ages need to be further studied preferably on human brain samples.

Very likely to previous studies [4], SH-SY5Y cells were shown to express P2X7, $\mathrm{P} 2 \mathrm{Y} 1, \mathrm{P} 2 \mathrm{Y} 2, \mathrm{P} 2 \mathrm{Y} 4$ and $\mathrm{P} 2 \mathrm{Y} 6$ receptors. However, in contrast to a recent study conducted by immunoblot analysis [4], we have also shown the expression of P2Y12 by SH-SY5Y cells using quantitative real time PCR analysis. This discrepancy might possibly be due to higher sensitivity of our quantitative PCR method.

Although a wide variety of $\mathrm{P} 2$ receptors has been shown to be expressed by neuroblastoma cells, little is known about the role of purinergic signalling in neuroblastoma progression and $\mathrm{P} 2 \mathrm{X} 7$, an ionotropic receptor, is the most extensively studied purinergic receptor in this context. P2X7 stimulation by ATP might be promoting neuroblastoma progression by enhancing release of locally acting trophic factors, maintaining calcium homeostasis through modulation of voltage-dependent calcium 
channel functions and activating the phosphatidylinositol 3-kinase (PI3K)-Akt cell survival pathway $[3,5,7,12]$. There is few evidence on the involvement of metabotropic $\mathrm{P} 2 \mathrm{Y}$ receptors in neuroblastoma progression. In this context, P2Y6 stimulation by UDP has been shown to exert a cytotoxic effect on human neuroblastoma SH-SY5Y cells [1]. In another study, transient activation of P2Y4 increased SH-SY5Y cell differentiation, while prolonged activation of the same receptor induced cell death [4].

In our study, we have shown that treatment of SH-SY5Y cells with non-selective global antagonists of $\mathrm{P} 2$ receptors, suramin and PPADS induces a remarkable but short-lived and transient reduction in cell viability, as measured by the MTT assay. We have also shown that PPADS has a longer duration of impact on SH-SY5Y cell viability than suramin. This reduced viability could potentially be due to reduced metabolic activity or reduced number of live cells or both. Our flow cytometry results suggest that P2 receptor antagonism has a marginal impact on cell death via necrotic but not apoptotic mechanisms. Also, this effect disappears at the 48th hour of treatment, while the viability reducing effect of PPADS continues at that time. Therefore, especially for PPADS, it is more likely that altered cellular metabolic activity is one of the mechanisms by which purinergic receptor antagonism reduces SH-SY5Y viability. Conceivably, suramin and PPADS might have altered cell survival via non-P2 receptor associated pathways or as a consequence of general toxicity. Therefore, utilization of cell lines that do not express $\mathrm{P} 2$ receptors is recommended to better characterize the involvement of $\mathrm{P} 2 \mathrm{X}$ and $\mathrm{P} 2 \mathrm{Y}$ receptors in cell survival.

Real time PCR studies showed that in concurrence with P2 antagonist-mediated reduction in cell viability, expression levels of all investigated $\mathrm{P} 2$ receptors were effectively altered. Although we have not identified the exact roles of $\mathrm{P} 2$ receptor expression changes in viability of neuroblastoma cells, certain conclusions can be drawn. P2Y6 receptor stimulation is known to cause toxicity in SH-SY5Y cells [1] and thus increased expression of this receptor following P2 antagonist treatment might have contributed to cell death via extracellular ATP released by neuroblastoma cells. P2X7 promotes neuroblastoma proliferation [5] and thus increased expression of this receptor might be a compensating measure to counteract decreased cell viability in the presence of purinergic antagonists. Short-term stimulation of P2Y4 leads to activation of differentiation pathways in SH-SY5Y cells [4] and thus downregulation of this receptor after antagonist treatment might also have led to reduced viability in neuroblastoma cells. Notably, while expression alterations of all P2 receptors were abolished at the 48th hour of the purinergic antagonist treatment, very likely to MTT assay results, the P2Y1 receptor expression kept being downregulated in PPADS but not suramin-treated cells. This suggests that selective prolonged inhibition of P2Y1 is the underlying factor for prolonged activity of PPADS. This notion needs to be supported by experiments conducted with selective P2Y1 receptor antagonists.

As a limitation of our study, we have not investigated $\mathrm{P} 2$ receptor production at protein level. It is well known that post-translational modifications might impede P2 receptor production and thus mRNA expression levels might not always reflect protein production levels of $\mathrm{P} 2$ receptors. Also, different post-translational modifications 
of P2 receptors may lead to activation of diverse pathways within the cell $[2,6]$. We did not study either the mechanisms underlying suramin- and PPADS-mediated P2 receptor expression changes. P2X4 receptor expression of microglial cells have recently been shown to be modulated by PI3K-Akt and mitogen-activated protein kinase kinase (MAPK kinase, MEK)-extracellular signal-regulated kinase (ERK) pathways. Moreover, a translational factor has been demonstrated to alter P2X4 receptor production through the MEK-ERK pathway [13]. Thus, parallel measurement of mRNA and protein level of $\mathrm{P} 2$ receptors and post-translational mechanisms controlling expression and intracellular functions of P2 receptors are recommended to be investigated in future experiments.

It is well known that different cancer types show varied viability patterns in response to purinergic antagonism depending on the panel of purinergic receptors expressed by individual cancer cells. For instance, Caco-2 human colonic cancer cells show increased viability in the presence of suramin and reduced viability when stimulated by purinergic agonists [15]. Our results show that the panel of receptors expressed by SH-SY5Y cells lead to reduced viability in response to purinergic antagonists. Overall, our results indicate that $\mathrm{P} 2$ antagonists might potentially be used as markers of treatment response for neuroblastoma patients and they might also serve as potential future targets for neuroblastoma treatment.

\section{ACKNOWLEDGEMENT}

This study was supported by the Research Fund of University of İstanbul, Project No: 48695.

\section{REFERENCES}

1. Apolloni, S., Finocchi, P., D'Agnano, I. et al. (2010) UDP exerts cytostatic and cytotoxic actions in human neuroblastoma SH-SY5Y cells over-expressing P2Y6 receptor. Neurochem. Int. 56, 670-678.

2. Bernier, L. P., Ase, A. R., Séguéla, P. (2013) Post-translational regulation of P2X receptor channels: modulation by phospholipids. Front. Cell. Neurosci. 7, 226.

3. Bianchi, G., Vuerich, M., Pellegatti, P. et al. (2014) ATP/P2X7 axis modulates myeloid-derived suppressor cell functions in neuroblastoma microenvironment. Cell. Death. Dis. 5, e1135.

4. Cavaliere, F., Nestola, V., Amadio, S. et al. (2005) The metabotropic P2Y4 receptor participates in the commitment to differentiation and cell death of human neuroblastoma SH-SY5Y cells. Neurobiol. Dis. $18,100-109$.

5. Gómez-Villafuertes, R., García-Huerta, P., Díaz-Hernández, J. I., Miras-Portugal, M. T. (2015) PI3K/ Akt signaling pathway triggers $\mathrm{P} 2 \mathrm{X} 7$ receptor expression as a pro-survival factor of neuroblastoma cells under limiting growth conditions. Sci. Rep. 5, 18417.

6. Kehasse, A., Rich, C. B., Lee, A. et al. (2013) Epithelial wounds induce differential phosphorylation changes in response to purinergic and EGF receptor activation. Am. J. Pathol. 183, 1841-1852.

7. Larsson, K. P., Hansen, A. J., Dissing, S. (2002) The human SH-SY5Y neuroblastoma cell-line expresses a functional $\mathrm{P} 2 \mathrm{X} 7$ purinoceptor that modulates voltage-dependent $\mathrm{Ca}_{2}+$ channel function. J. Neurochem. 83, 285-298.

8. McConville, C. M., Forsyth, J. (2003) Neuroblastoma - a developmental perspective. Cancer. Lett. 197, 3-9.

9. Miao, L. Y., Tang, J. P., Esposito, D. P., Zhang, J. H. (2001) Age-related changes in P2 receptor mRNA of rat cerebral arteries. Exp. Gerontol. 37, 67-79. 
10. North, R. A. (2002) Molecular physiology of P2X receptors. Physiol. Rev. 82, 1013-1067.

11. Puchałowicz, K., Tarnowski, M., Baranowska-Bosiacka, I., Chlubek, D., Dziedziejko, V. (2014) P2X and P2Y receptors-role in the pathophysiology of the nervous system. Int. J. Mol. Sci. 15, 2367223704.

12. Raffaghello, L., Chiozzi, P., Falzoni, S., Di Virgilio, F., Pistoia, V. (2006) The P2X7 receptor sustains the growth of human neuroblastoma cells through a substance P-dependent mechanism. Cancer. Res. 66, 907-914.

13. Tsuda, M., Toyomitsu, E., Kometani, M., Tozaki-Saitoh, H., Inoue, K. (2009) Mechanisms underlying fibronectin-induced up-regulation of P2X4R expression in microglia: distinct roles of PI3K-Akt and MEK-ERK signalling pathways. J. Cell. Mol. Med. 13, 3251-3259.

14. Woods, L. T., Ajit, D., Camden, J. M., Erb, L., Weisman, G. A. (2016) Purinergic receptors as potential therapeutic targets in Alzheimer's disease. Neuropharmacology 104, 169-179.

15. Yaguchi, T., Saito, M., Yasuda, Y., Kanno, T., Nakano, T., Nishizaki, T. (2010) Higher concentrations of extracellular ATP suppress proliferation of Caco-2 human colonic cancer cells via an unknown receptor involving PKC inhibition. Cell. Physiol. Biochem. 26, 125-134. 